Check for updates

Cite this: RSC Adv., 2019, 9, 34744

Received 20th September 2019 Accepted 21st October 2019

DOI: 10.1039/c9ra07623a

rsc.li/rsc-advances

\section{Study on water resistance and tribological behaviours of basalt fibre/acrylonitrile-butadiene rubber composites under water lubrication at various temperatures}

\author{
Zhuo Li, (D)* Yingzhe Li, Yue Xiao, Yihan Yang and Lin Li \\ In this study, the effects of water ageing on characteristics and properties of basalt fibre (BF)/acrylonitrile- \\ butadiene rubber (NBR) composites were investigated, and the tribological behaviours of the composites \\ that slide against the stainless-steel counterpart under water lubrication at $30-70{ }^{\circ} \mathrm{C}$ were the main \\ focus. Results showed that with the water temperature increase, the hardness and tear strength of the \\ water-aged samples decreased. Furthermore, both the friction coefficient (COF) and specific wear rate \\ $\left(W_{s}\right)$ of the composites increased with the temperature. The content and the orientation of BFs had no \\ obvious effect on the COF, whereas the parallel-aligned BFs were effective at improving the wear \\ resistance of the composites at both $30^{\circ} \mathrm{C}$ and $70{ }^{\circ} \mathrm{C}$.
}

\section{Introduction}

Traditionally, the marine stern tube bearing is lubricated by lubricating oils and grease, and the water environmental pollution caused by its leakage has provoked worries, especially with the sharp increase of its applications..$^{1-3}$ To solve this problem, water-lubricated bearings were proposed to replace the oil-lubricated bearings and have attracted more attention in recent decades. ${ }^{4-10}$ For optimal lubricating effect, a continuous water film should be formed between the shaft and the bearing. Rubber is a type of material well lubricated by water, and acrylonitrile-butadiene rubber (NBR) is widely used for waterlubricated bearings thanks to its chemical stability, vibration absorption ability and relatively high resistance to fatigue and wear. ${ }^{1,11-13}$ The wear behaviour of the rubber materials under actual service conditions requires great attention, since excessive wear on the rubber stern tube bearings is one of the most important reasons for the loss of workability. ${ }^{14-16}$ Some literatures have reported the effects of actual working conditions, such as sand in the water and improper lubrication and cooling, ${ }^{1,12}$ on the tribological properties of NBR composites. Another environmental factor which affects the tribological behaviours of the water-lubricated bearings is the temperature. The bearings may experience various temperatures due to the environmental conditions and heat generation by friction. Some researchers have mentioned the increase of the friction coefficient (COF) with the temperature. ${ }^{17-19}$ However, the effect

Key Laboratory of Rubber-Plastics, Ministry of Education/Shandong Provincial Key Laboratory of Rubber-Plastics, Qingdao University of Science \& Technology, Qingdao 266042, China. E-mail: lizhuoqust@126.com and mechanism of temperature changes on tribological behaviours of NBR composites have not been systematically studied.

To improve the tribological performance (especially at relatively high temperature) of the NBR composites, one of the options is introducing high-performance fibres. In recent years, basalt fibre (BF), which is a novel type of eco-friendly mineral fibre with excellent comprehensive properties and relatively low cost, has been introduced as reinforcement of the composites and its effects on the tribological properties were mentioned in several publications., ${ }^{4,20}$ Zhang et al. ${ }^{23}$ reported that the addition of BFs improved the hardness, compressive strength and creep resistance of the polyetheretherketone (PEEK)-based composites, and a BF/PEEK composite with 2.5-7.5 phr BFs possessed a low COF and excellent wear resistance. In our previous work,,$^{25,26} \mathrm{BFs}$ were mixed into the NBR as reinforcement, and it was demonstrated that when sliding against the stainless steel counterface under dry condition, the addition of BFs could decrease both the COF and the wear rate. For the water-lubricated bearing application, understanding the tribological performance of the material under water lubrication is very important for the property assessment and life prediction of the product. In this study, the tribological behaviour of $\mathrm{BF} / \mathrm{NBR}$ composites under water-lubricated conditions at $30-70{ }^{\circ} \mathrm{C}$ was investigated using a block-on-ring test, which has been widely applied to study the tribological performance of polymer composites for bearing application. ${ }^{27-30}$ To discuss the effect mechanism, the influences of water ageing on the properties of $\mathrm{BF} / \mathrm{NBR}$ composites were also evaluated. 


\section{Experimental}

\subsection{Materials}

The NBR (NANCAR1051, acrylonitrile content 41\%) was purchased from the Nantex Industry Co., Ltd., Zhenjiang, China. The NBR was plasticated before use (Mooney viscosity ML (1 + 4) $100{ }^{\circ} \mathrm{C}$ : 60-63). Continuous BF (BC11-200, filament diameter $11 \mu \mathrm{m} \pm 2 \mu \mathrm{m}$ ) was supplied by the Sichuan Aerospace Tuoxin Industrial Co., Ltd., China, and cut into $4 \mathrm{~mm}$ lengths by a cutting machine in our laboratory. The chopped BFs were soaked in acetone for $50 \mathrm{~min}$, washed with distilled water three times and vacuum dried at $105{ }^{\circ} \mathrm{C}$ for $6 \mathrm{~h}$ before use. Carbon black (CB) N550 was supplied by the Kabote (China) Investment Co., Ltd. N-Cyclohexyl-2-benzothiazole sulphonamide (CBS) was supplied by Puyang Willing Chemicals, China. Other reagents, including $\mathrm{ZnO}$, stearic acid (SA), polymerized 1,2-dihydro-2,2,4-trimethylquinoline (TMQ), dioctyl phthalate (DOP) and insoluble sulphur, were commercially available and used as received.

\section{2. $\mathrm{BF} / \mathrm{NBR}$ composites preparation}

The components of the BF/NBR composites are shown in Table 1, and the following mixing process was used to prepare the composites with various $\mathrm{BF}$ contents and orientation. NBR, ZnO, SA, TMQ, CB and DOP were first mixed in an internal mixer at an initial temperature of $90{ }^{\circ} \mathrm{C}$ for $8 \mathrm{~min}$. Then, the compound was moved to a two-roll mill. CBS and insoluble sulphur were added into the blends first, and after the blends were fully mixed, the BFs $(0,3,12,20,30 \mathrm{phr}$, separately) were added into the compounds and further rolled for 5 min $40 \mathrm{~s}$ to ensure that the BFs were sufficiently oriented along the rolling direction. To obtain the cured samples with $\mathrm{BF}$ parallel and perpendicular orientation, the blends were cut parallel and perpendicular to the rolling direction, respectively, and then were vulcanized at $155{ }^{\circ} \mathrm{C}$ at a pressure of $10 \mathrm{MPa}$ for $15 \mathrm{~min}$. The samples were denoted according to the $\mathrm{BF}$ content and orientation. For example, the samples with $12 \mathrm{phr}$ BFs oriented in the parallel and perpendicular directions were named as BF12-pa and BF12-per, respectively. The vulcanized samples were stored at room temperature for $16 \mathrm{~h}$ before further ageing or performance evaluation.

\subsection{Water ageing}

According to GB/T 1690-2010, the BF/NBR composites prepared in Section 2.2 were soaked in water and were aged at $30^{\circ} \mathrm{C}, 50{ }^{\circ} \mathrm{C}$ and $70{ }^{\circ} \mathrm{C}$ for $72 \mathrm{~h}$, respectively. For the water absorption ratio test, the samples $\left(25 \times 25 \times 2 \mathrm{~mm}^{3}\right)$ were weighed before ageing to obtain $M_{1}$, and after ageing, the samples were wiped by a blotter and weighed immediately to obtain $M_{2}$; the water absorption ratio was calculated according to eqn (1):

$$
\text { Water absorption ratio }(\%)=\frac{M_{2}-M_{1}}{M_{1}} \times 100 \%
$$

Three specimens were tested for each type of samples.
Table 1 Composition of the BF/NBR composites

\begin{tabular}{ll}
\hline Component & Content (phr) \\
\hline NBR & 100 \\
ZnO & 5 \\
SA & 1 \\
CB N550 & 50 \\
TMQ & 1.2 \\
DOP & 10 \\
CBS & 1 \\
Insoluble sulphur & 1.5 \\
BF & $0 / 3 / 12 / 20 / 30$
\end{tabular}

\subsection{Measurements}

The hardness of the rubber vulcanizates was evaluated using a Shore A hardness tester (GT-GS-MB, Gotech Testing Machines Co., Ltd.) according to GB/T 531.1-2008, and 3 points were measured for each sample. The density of the rubber vulcanizates was tested according to GB/T 533-2008, and 3 specimens were tested for each sample type. The tensile and tear properties of the vulcanized rubber were tested using a Z005 universal testing machine (Germany) at a drawing rate of $500 \mathrm{~mm} \mathrm{~min}^{-1}$ according to the standards GB/T 528-2009 and GB/T 529-2008, respectively. The $T_{2}$ (transverse relaxation time) of the vulcanizates before and after water ageing was tested using nuclear magnetic resonance (NMR, MR-CDS3500) from IIC Innovative Imaging Co., Ltd., Germany. The measured values were fitted with the Gauss-exponential magnetization decay equation (eqn (2)) and the $T_{2}$ (transverse relaxation time) was obtained.

$$
M(t)=A+B \mathrm{e}^{-\frac{t}{T_{2}}-q M_{2} t^{2}}+C \mathrm{e}^{-\frac{t}{T_{2}}}
$$

in which $q M_{2}$ means the residual dipole moment; $A, B$, and $C$ are the parameters without special definition. The samples were dried in a dryer for $24 \mathrm{~h}$ before the test.

The friction and wear tests were performed on a high-speed block-on-ring wear testing machine (MR-H3B, Jinan Time Shijin Testing Machine Co., Ltd., China), under water lubrication at $30{ }^{\circ} \mathrm{C}, 50{ }^{\circ} \mathrm{C}$ and $70{ }^{\circ} \mathrm{C}$, respectively. The BF/NBR block, the 304\# stainless steel ring and the test apparatus are as shown in Fig. 1(a), (b) and (c), respectively. The test was carried out with a sliding speed of $1.03 \mathrm{~m} \mathrm{~s}^{-1}$ and a normal load of $40 \mathrm{~N}$ for $90 \mathrm{~min}$. The $W_{\mathrm{s}}$ was calculated according to eqn (3), and the volume of wear scar $\left(V_{\mathrm{s}}\right)$ was obtained according to eqn (4). ${ }^{27}$

$$
\begin{gathered}
W_{\mathrm{s}}=\frac{V_{\mathrm{s}}}{F 2 \pi R n t} \\
V_{\mathrm{s}}=\left[\frac{\pi}{180} R^{2} \arcsin \frac{b}{2 R}-\frac{b}{2} \sqrt{R^{2}-\frac{b^{2}}{4}}\right] B
\end{gathered}
$$

where $F$ is the normal load $(\mathrm{N}), R$ is the radius of the steel ring $(\mathrm{mm}), b$ is the width of the wear scar $(\mathrm{mm}), B$ is the width of the rubber block (mm), $n$ is the sliding speed (rpm), and $t$ is the steady duration of the friction ( $\mathrm{min}$ ). The mean value of the COF and $W_{\mathrm{s}}$ was calculated based on the results of 3 specimens. 
(a)

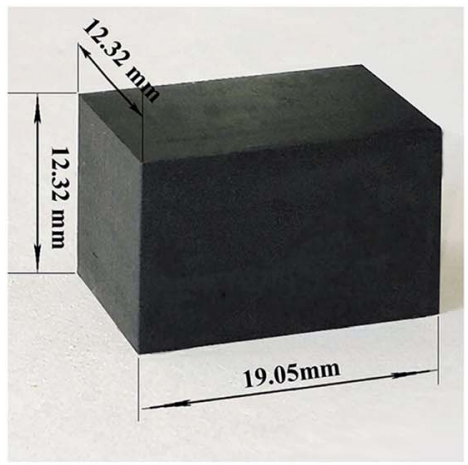

(b)

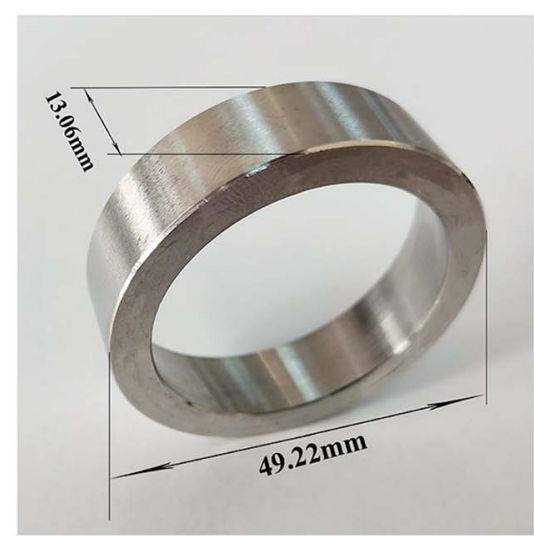

(c)

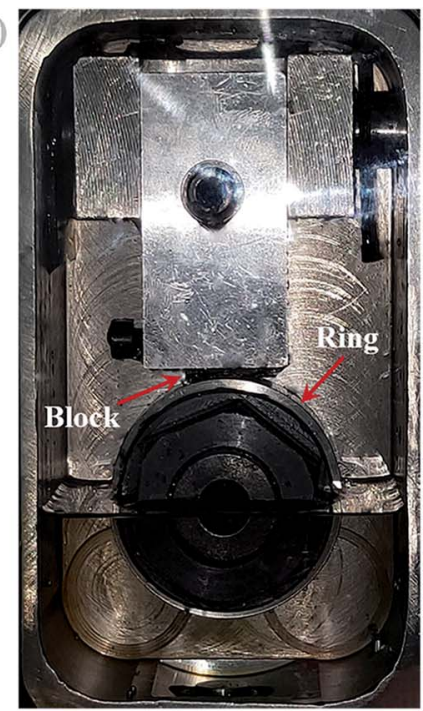

Fig. 1 Images of the (a) BF/NBR block, (b) stainless steel ring and (c) the main part of the test apparatus.

The worn surfaces of the BF/NBR composites in the blockon-ring tests were observed using a JEOL JSM-7500F scanning electron microscope (SEM), and the worn surfaces of the steel counterparts were observed using a stereomicroscope (SMZ1500, Nikon, Japan).

\section{Results and discussion}

\subsection{Water ageing}

Table 2 shows the water absorption ratio and variations in the density of BF/NBR composites before and after $72 \mathrm{~h}$ water immersion at $30{ }^{\circ} \mathrm{C}, 50{ }^{\circ} \mathrm{C}$ and $70{ }^{\circ} \mathrm{C}$, respectively. With the temperature increase, the water absorption ratio of the composites increased and was independent of the $\mathrm{BF}$ content. In our previous study, ${ }^{25}$ the NMR test showed that the $T_{2}$ of the thermal-oxidative-aged NBR samples was lower than that of the initial one, which indicated further crosslinking during the ageing process. However, water ageing at temperatures above $50{ }^{\circ} \mathrm{C}$ led to an increase of the $T_{2}$ of the samples (the typical magnetization intensity curves of the NBR vulcanizates are as shown in Fig. 2); the $T_{2}$ of the initial NBR vulcanizate and the samples after water ageing at $30{ }^{\circ} \mathrm{C}, 50{ }^{\circ} \mathrm{C}$ and $70{ }^{\circ} \mathrm{C}$ were $1.11,1.08,1.29$ and $1.24 \mathrm{~ms}$, respectively. The increase of the $T_{2}$ reflected the move ability improvement of the $\mathrm{H}$ in the system, which may be caused by hydrolysis of $-\mathrm{CN}$ and the generation of $-\mathrm{CONH}_{2}$ and $-\mathrm{COOH}$ when the sample was immersed in the water at temperatures above $50{ }^{\circ} \mathrm{C}$. Furthermore, as shown in Table 3, the hardness of the samples decreased after ageing, and the addition of BFs failed to enhance the hardness of the water-aged composites, especially at $50{ }^{\circ} \mathrm{C}$ and $70{ }^{\circ} \mathrm{C}$. The decrease of the hardness should be attributed to the water absorption, and as concluded by Wang et al. ${ }^{4}$ diffusion through fibre/matrix interface is the predominant water absorption mechanism of fibre-reinforced polymer composites. According to this mechanism, the weak connection between the BF and the NBR matrix, which produced extensive interfacial free space around the fibre (Fig. 3), led to water aggregation and weakened the BF enhancement in hardness; when ageing in higher temperature, the water absorption was increased, and the aggregation of water in the BF/NBR interface was aggravated. However, after being fully dried, the hardness of the aged samples was basically the same as that of the untreated samples, which indicated that no crosslinking density change of the NBR matrix had occurred. The hardness of the composites under various temperatures in air is shown in Fig. 4. As the temperature increased, the hardness of the composites decreased due to the softening of the matrix.

Table 2 Water absorption ratio and density of BF/NBR composites before and after $72 \mathrm{~h}$ water immersion at various temperatures

\begin{tabular}{|c|c|c|c|c|c|c|c|}
\hline & \multicolumn{3}{|c|}{ Water absorption ratio/\% } & \multicolumn{4}{|c|}{ Density $/ \mathrm{g} \mathrm{cm}^{-3}$} \\
\hline & $30{ }^{\circ} \mathrm{C}$ & $50{ }^{\circ} \mathrm{C}$ & $70{ }^{\circ} \mathrm{C}$ & Before aging & $30^{\circ} \mathrm{C}$ & $50^{\circ} \mathrm{C}$ & $70^{\circ} \mathrm{C}$ \\
\hline BF3 & $1.32 \pm 0.040$ & $4.58 \pm 0.062$ & $6.97 \pm 0.111$ & 1.20 & 1.20 & 1.19 & 1.19 \\
\hline BF12 & $1.30 \pm 0.036$ & $4.59 \pm 0.028$ & $7.19 \pm 0.140$ & 1.23 & 1.22 & 1.23 & 1.22 \\
\hline BF20 & $1.24 \pm 0.082$ & $4.58 \pm 0.047$ & $7.16 \pm 0.068$ & 1.26 & 1.26 & 1.24 & 1.24 \\
\hline
\end{tabular}




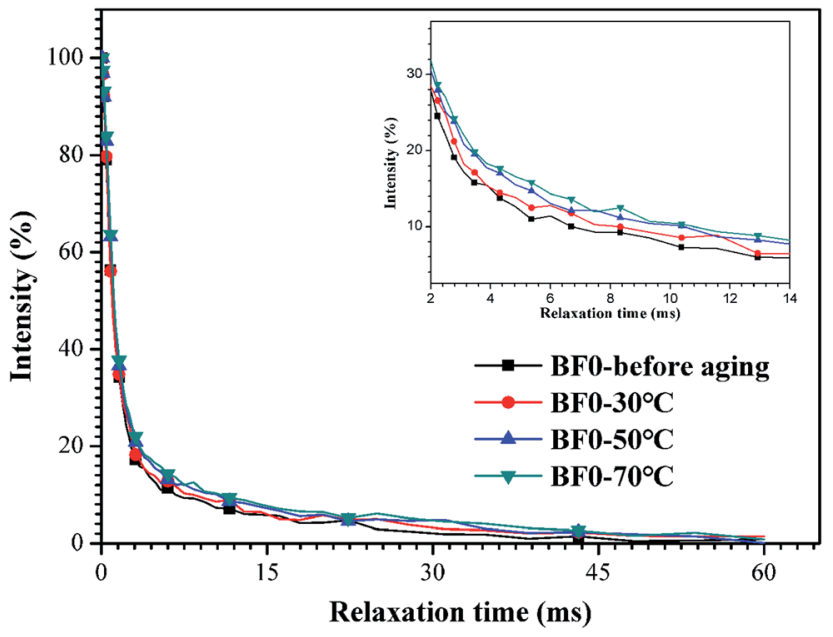

Fig. 2 The magnetization intensity curves of the NBR vulcanizates before and after water ageing for $72 \mathrm{~h}$ at $30{ }^{\circ} \mathrm{C}, 50{ }^{\circ} \mathrm{C}$ and $70{ }^{\circ} \mathrm{C}$.

The effects of water ageing on the rebound resilience, tensile properties and tear strength of the BF/NBR composites are as shown in Fig. 5, 6 and 7, respectively. With the water temperature rising, the rebound resilience of the aged composites obviously improved due to the increase of the water absorption. Furthermore, with regard to the mechanical properties, the influences of the water ageing on the tensile properties were relatively low. For example, the tensile strength, elongation at the break and modulus at $300 \%$ of BF12-pa water-aged for $72 \mathrm{~h}$ at $70{ }^{\circ} \mathrm{C}$, were $92 \%, 103 \%$, and $105 \%$ of that of the initial reading, respectively. However, the tear strength of the BF/NBR composites with a high $\mathrm{BF}$ content were more sensitive to the water ageing.

\subsection{Friction and wear}

3.2.1 COF. The typical variations of COFs for the NBR block and $304 \#$ stainless steel ring rubbing pairs as a function of the

Table 3 Hardness of BF/NBR composites before and after $72 \mathrm{~h}$ water immersion at various temperatures

\begin{tabular}{|c|c|c|c|c|c|}
\hline & \multicolumn{5}{|c|}{ Shore A hardness } \\
\hline & BF0 & BF3 & BF12 & BF20 & BF30 \\
\hline Before ageing & 63 & 64 & 66 & 67 & 70 \\
\hline \multicolumn{6}{|l|}{$30^{\circ} \mathrm{C}$ water ageing } \\
\hline Aged sample & 61 & 62 & 62 & 62 & 64 \\
\hline Aged-dried sample ${ }^{a}$ & 63 & 64 & 66 & 66 & 69 \\
\hline \multicolumn{6}{|l|}{$50{ }^{\circ} \mathrm{C}$ water ageing } \\
\hline Aged sample & 60 & 60 & 60 & 61 & 61 \\
\hline Aged-dried sample & 63 & 64 & 66 & 66 & 68 \\
\hline \multicolumn{6}{|l|}{$70{ }^{\circ} \mathrm{C}$ water ageing } \\
\hline Aged sample & 58 & 58 & 57 & 58 & 58 \\
\hline Aged-dried sample & 63 & 63 & 65 & 65 & 69 \\
\hline
\end{tabular}

${ }^{a}$ The aged samples were dried in a drier for $24 \mathrm{~h}$ before the test.

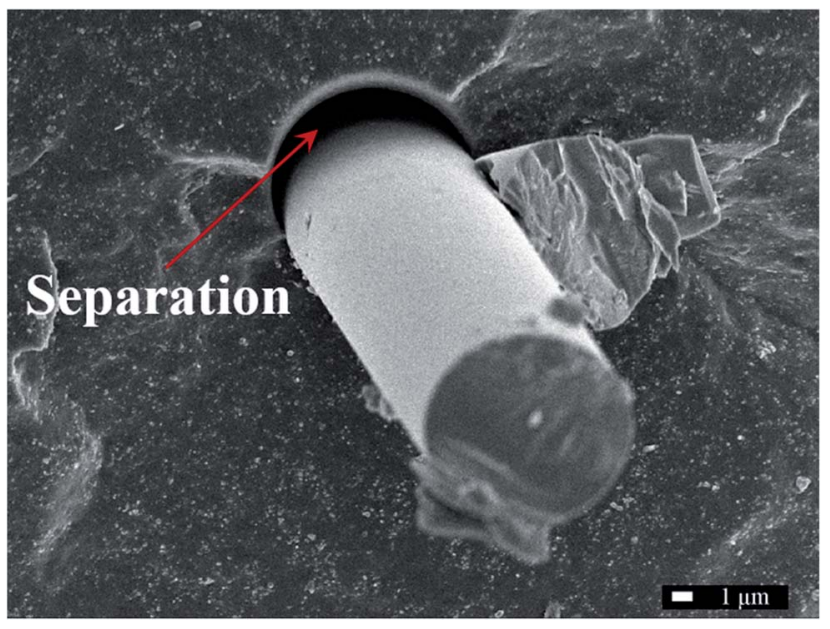

Fig. 3 The SEM image of the BF/NBR interface (the brittle fracture sample, $3000 \times$ ).

sliding time under water-lubricated conditions at $30{ }^{\circ} \mathrm{C}, 50{ }^{\circ} \mathrm{C}$ and $70^{\circ} \mathrm{C}$ are as shown in Fig. 8, and the COFs obtained under dry sliding conditions in our previous work ${ }^{26}$ are also included as a reference. In general, the COF of the NBR/stainless steel stayed relatively stable throughout the sliding under waterlubrication at various temperatures and was much lower than that obtained under dry sliding conditions due to the formation of the water film between the rubbing pairs. Furthermore, the $\mathrm{COF}$ increased with the temperature from $30{ }^{\circ} \mathrm{C}$ to $70{ }^{\circ} \mathrm{C}$. This variation should be attributed to the effect of the temperature on the water viscosity. The viscosity of water is $0.7977,0.5470$ and $0.4040 \mathrm{mN} \mathrm{s} \mathrm{m}{ }^{-2}$ at $30{ }^{\circ} \mathrm{C}, 50{ }^{\circ} \mathrm{C}$ and $70{ }^{\circ} \mathrm{C}$, respectively, ${ }^{31}$ which shows a sharp decrease with the temperature rise. The decrease of water viscosity was not conducive to the formation of the continuous water film between the rubbing pairs, and as a result, the lubricating capacity of the water decreased. By comparison, as shown in Fig. 9, the BF content showed less

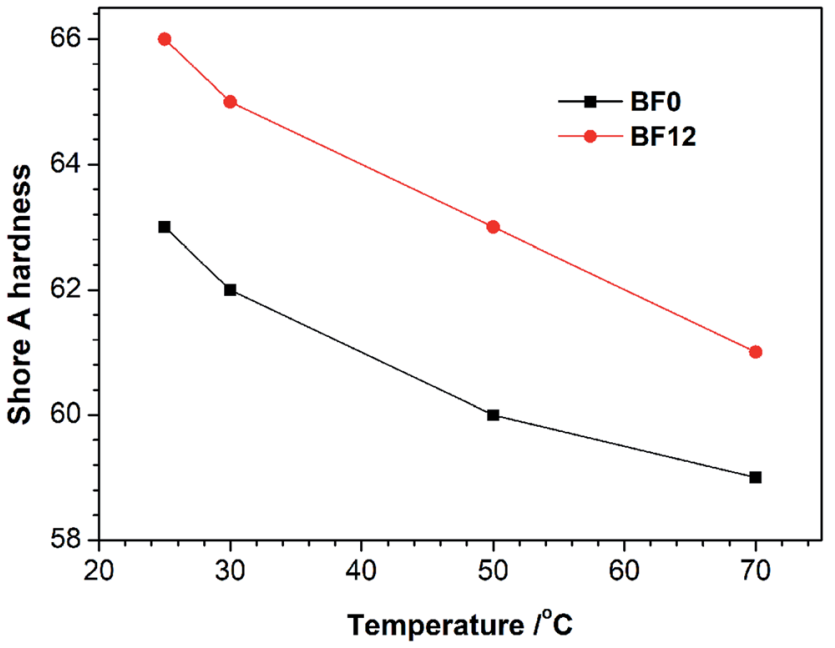

Fig. 4 Effects of the temperature on the Shore A hardness of BF/NBR composites in air. 

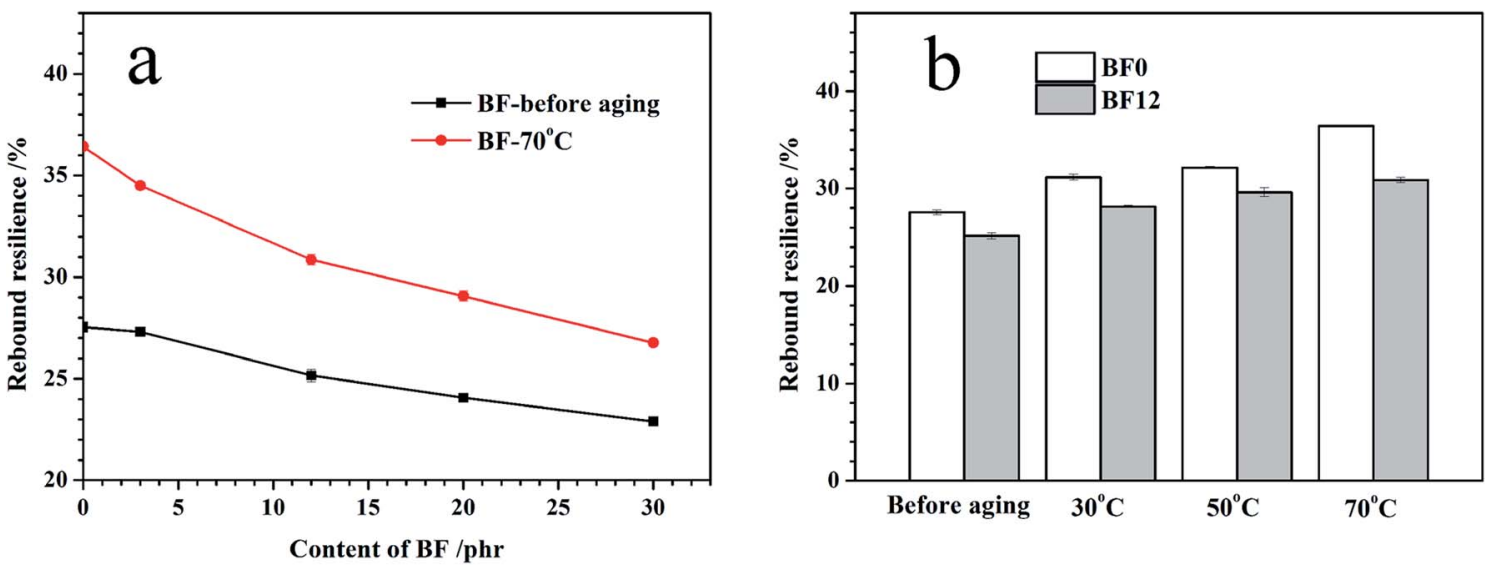

Fig. 5 Effects of (a) the BF content and (b) the temperature of water ageing on the rebound resilience of BF/NBR composites.

impact on the COF. Although the hardness of water-absorbed NBR decreased, especially at high temperatures (as discussed in Section 3.1), and led to an increase of the contact area between the block and the ring during the sliding and inclined to increase the friction force, the lubrication condition played a critical role in determining the COF.

3.2.2 $W_{s}$. The effects of the temperature, the BF content and the orientation on the $W_{\mathrm{s}}$ of the $\mathrm{BF} / \mathrm{NBR}$ composites abraded under water-lubricated conditions are shown in Fig. 10. The water lubrication showed a significant effect on decreasing

the wear loss of the BF/NBR composites. Furthermore, as shown in Fig. 10a, for the friction system that is lubricated by $30{ }^{\circ} \mathrm{C}$ water, when the BFs were parallel oriented, the $W_{\mathrm{s}}$ obviously decreased with the $\mathrm{BF}$ content increase, whereas the $W_{\mathrm{s}}$ was kept approximately constant when the BFs were perpendicularly-aligned. When the system was lubricated by $70{ }^{\circ} \mathrm{C}$ water, the addition of BFs with either parallel or perpendicular orientation was effective in improving the wear resistance; after sliding at $70^{\circ} \mathrm{C}$, the $W_{\mathrm{S}} \mathrm{S}$ of BF30-pa and BF30per were 1.3 and $1.6 \times 10^{-7} \mathrm{~mm}^{3} \mathrm{~N}^{-1} \mathrm{~mm}^{-1}$, which were $62 \%$

b
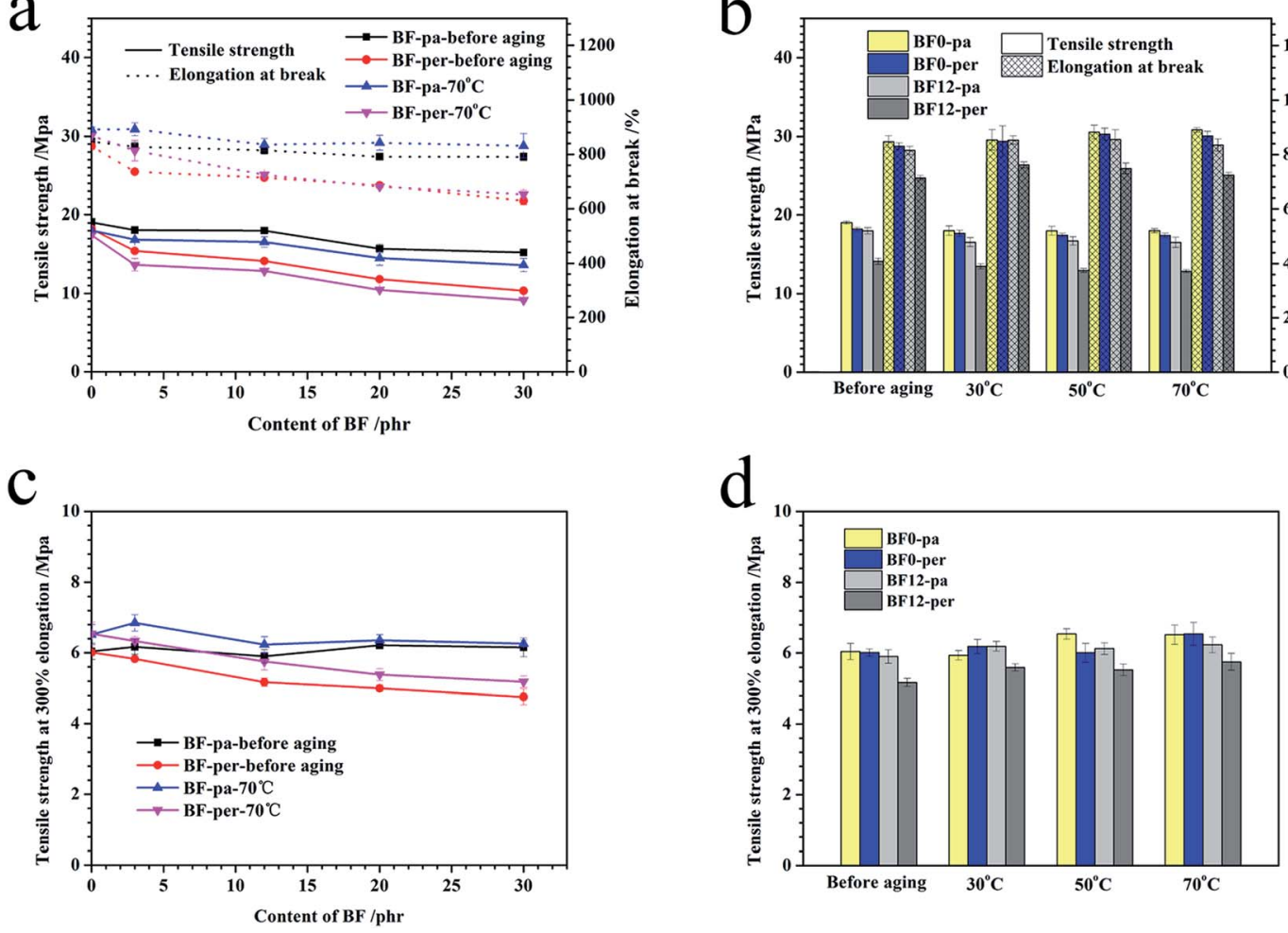

Fig. 6 Effects of the BF content and the temperature of water ageing on the tensile properties of the BF/NBR composites. (a) Tensile strength and elongation at break vs. content of the BF; (b) tensile strength and elongation at break vs. temperature of water ageing; (c) tensile strength at $300 \%$ elongation vs. content of BF; and (d) tensile strength at $300 \%$ elongation vs. temperature of water ageing. 

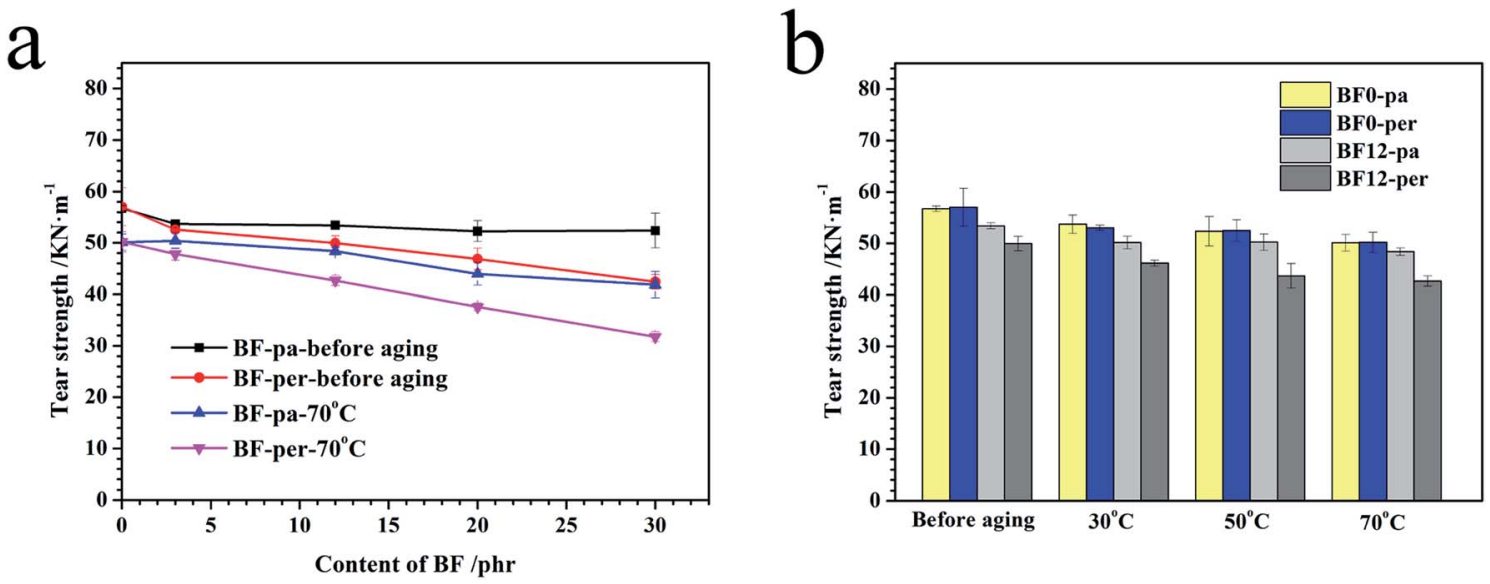

Fig. 7 Effects of (a) the BF content/orientation and (b) the temperature of water ageing on the tear strength of BF/NBR composites.

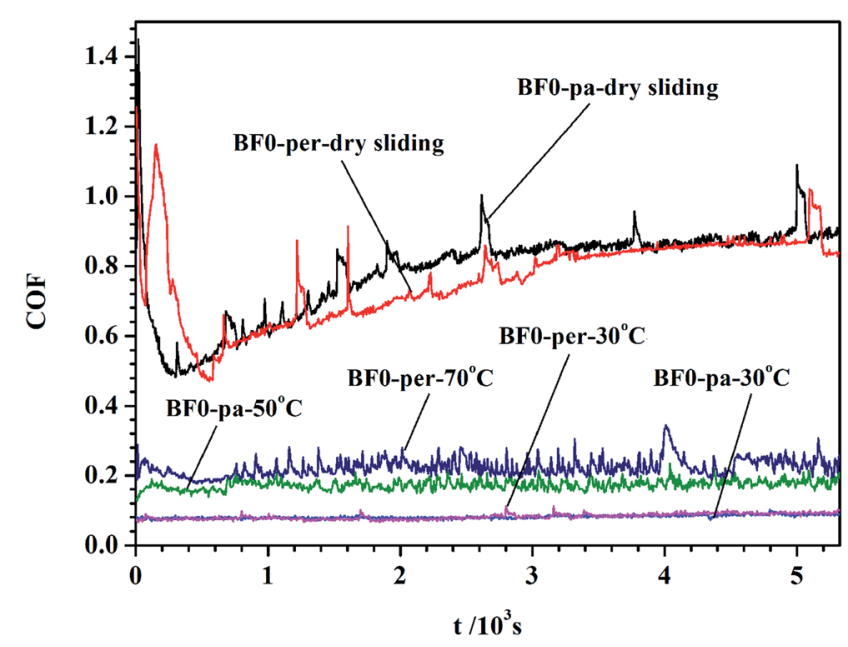

Fig. 8 Typical COFs of the NBR as a function of sliding time under dry sliding and water lubrication at various temperatures.

and $73 \%$ of the BF0-pa and BF0-per, respectively. The efficiency improvement of the perpendicularly orientated BFs should be due to the insufficient water lubrication at high temperature, and the effects of the BFs were similar to those under dry sliding conditions, to some extent. Wang et $a .^{4}{ }^{4}$ reported that the addition of the BFs significantly increased the wear rate of the PTFE-based composites due to poor adhesion between the BF and the matrix, but this increase did not happen in the $\mathrm{BF} / \mathrm{NBR}$ composites. This is because, as shown in Section 3.1, the water absorption ratio was not mainly affected by the BF content, and furthermore, mechanical properties of the BF/NBR composites did not significantly change after water absorption, which means that the water absorption did not lead to significant plasticization of the NBR matrix, as it did in the PTFE. In this study, the orientation of the BFs, besides the water temperature, was the primary factor in determining the $W_{\mathrm{s}}$.

To further investigate the wear mechanism, the worn surfaces of BF/NBR blocks and the steel rings were observed by an SEM and stereomicroscope, respectively. As shown in Fig. 11, there is no visible rubber transfer film on the counterface, which should be attributed to the isolation effect of the water film. Furthermore, after friction occurred with water lubrication at $30{ }^{\circ} \mathrm{C}$, only a few scratches could be observed on the steel counterface, whereas the friction that occurred with $70{ }^{\circ} \mathrm{C}$ water lubrication led to severe scratches
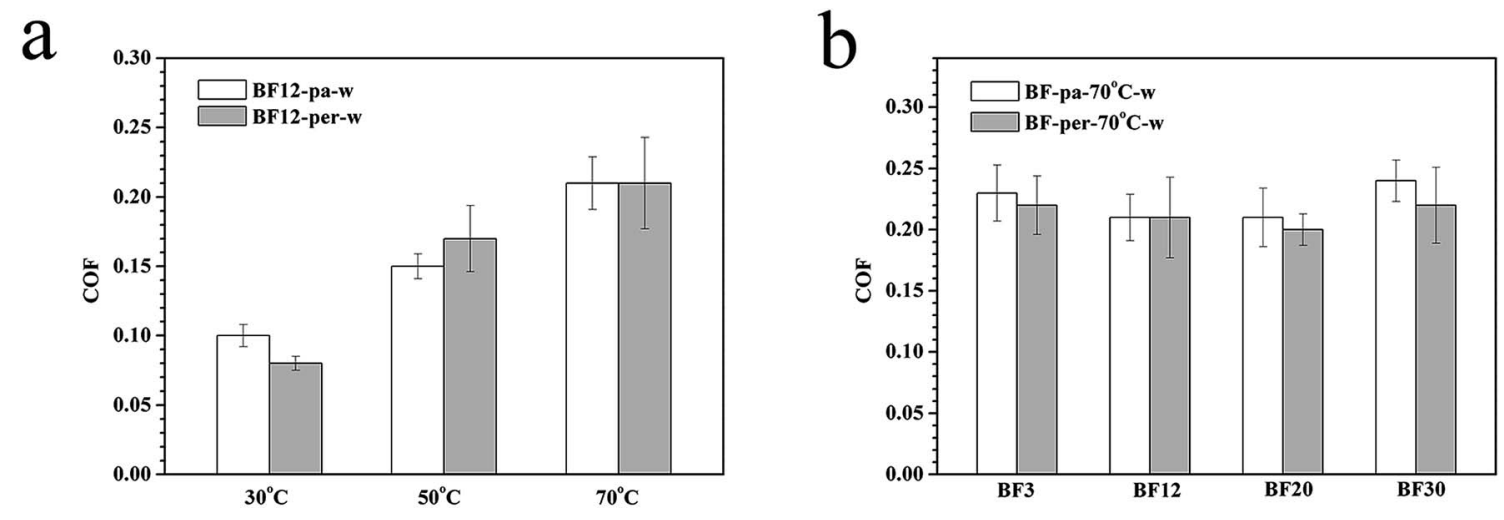

Fig. 9 (a) The COFs of the BF/NBR composites with 12 phr BFs under water lubrication at various temperatures, and (b) the COFs of the BF/NBR composites with various contents and orientation of BFs under water lubrication at $70{ }^{\circ} \mathrm{C}$. 

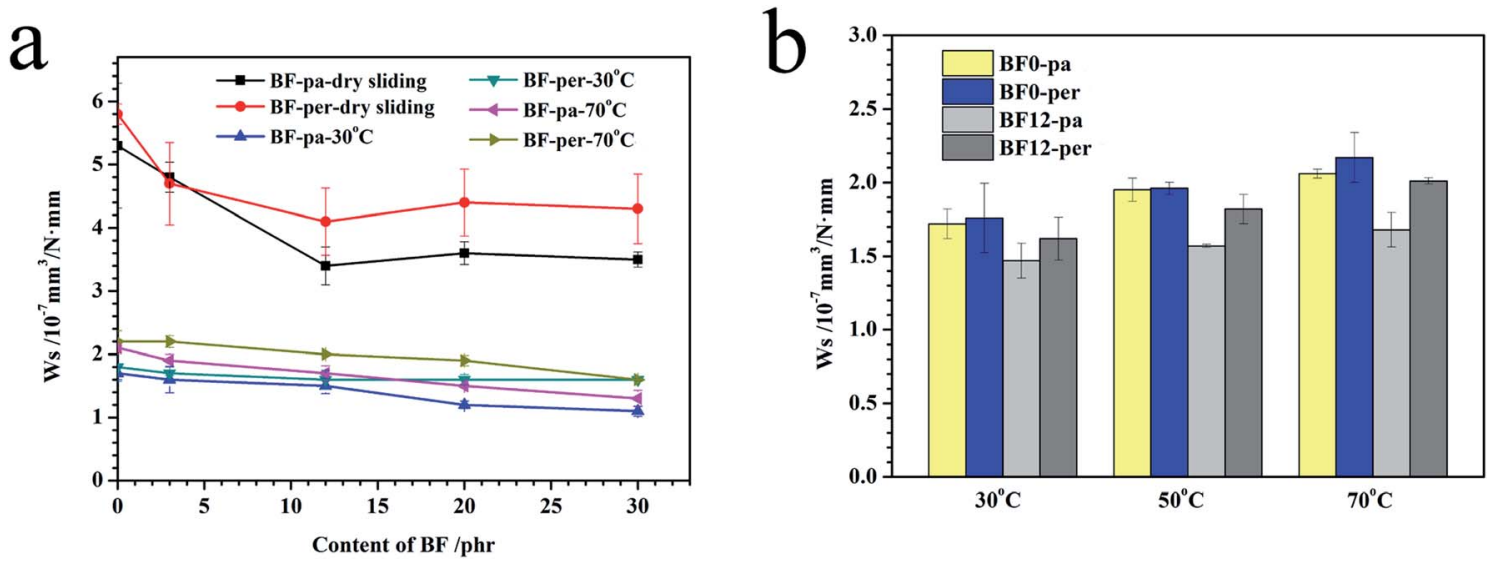

Fig. 10 Effects of (a) the BF content/orientation and (b) the water temperature on the $W_{s}$ of BF/NBR composites.

along the sliding direction, which should be attributed to insufficient water lubrication.

Similar to the steel ring, the temperature of the system, rather than the $\mathrm{BF}$ content/orientation, had a major effect on the wear morphologies of the BF/NBR. Fig. 12 and 13 show the SEM images of the surfaces of the $\mathrm{BF} / \mathrm{NBR}$ composites with various $\mathrm{BF}$ contents worn under $30^{\circ} \mathrm{C}$ and $70{ }^{\circ} \mathrm{C}$ water lubrication, respectively. In general, the wear degree of the $\mathrm{BF} / \mathrm{NBR}$ blocks under water-lubricated conditions was much lower than that of the block friction under dry sliding conditions (in ref. 25 and 26). Fig. 14 illustrates the influences of the water during the sliding process. First, the water film formed between the rubbing pair and effectively reduced the friction, and second, the debris was taken away by water and the abrasive wear was reduced. For the samples that were rubbed under water lubrication at $30{ }^{\circ} \mathrm{C}$, the BF30-per had a rougher surface than the others did. Compared with the parallel-oriented BFs, the perpendicularly oriented fibres were more easily crushed under a relatively high load ( $40 \mathrm{~N}$ in this study) because of the larger contact area with the steel counterpart during the rubbing. It has been speculated that the stripping and the rubbing of the BFs with high content and perpendicular orientation may have led to a relatively high heat production and, as a result, the adhesive wear was aggravated.

Furthermore, in comparing with the images in Fig. 12 and 13 , it was revealed that the surface of the BF/NBR block worn under water lubrication at higher temperatures was much rougher, and delamination and cracks can be observed after
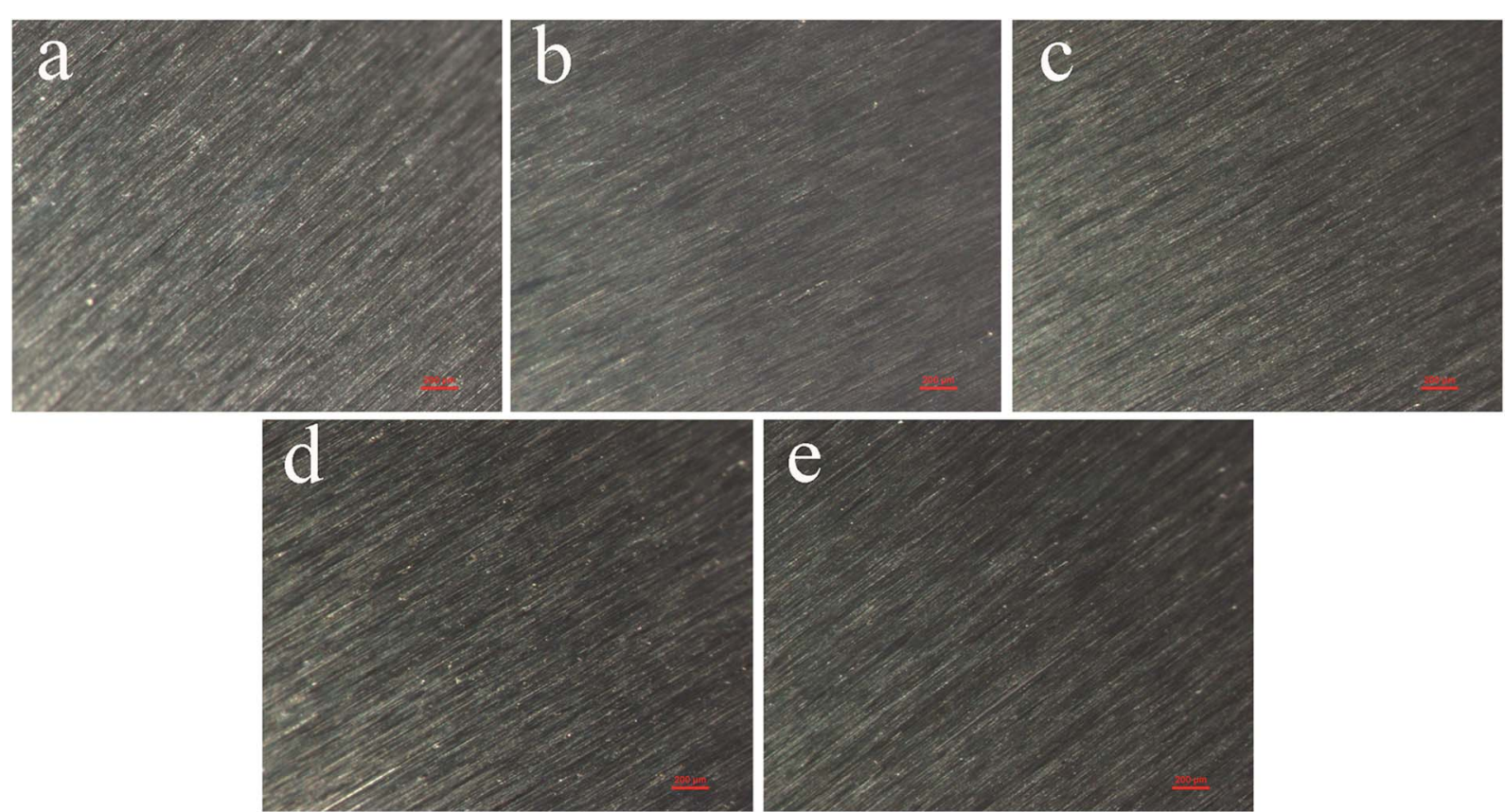

Fig. 11 Typical morphologies $(40 \times)$ of (a) the initial steel counterpart surface and the steel counterpart surface after rubbing with the block of (b) BF12-pa-30 ${ }^{\circ} \mathrm{C}$; (c) BF-12-per-30 ${ }^{\circ} \mathrm{C}$; (d) BF12-pa-70 ${ }^{\circ} \mathrm{C}$; (e) BF12-per-70 ${ }^{\circ} \mathrm{C}$ under water lubrication. 

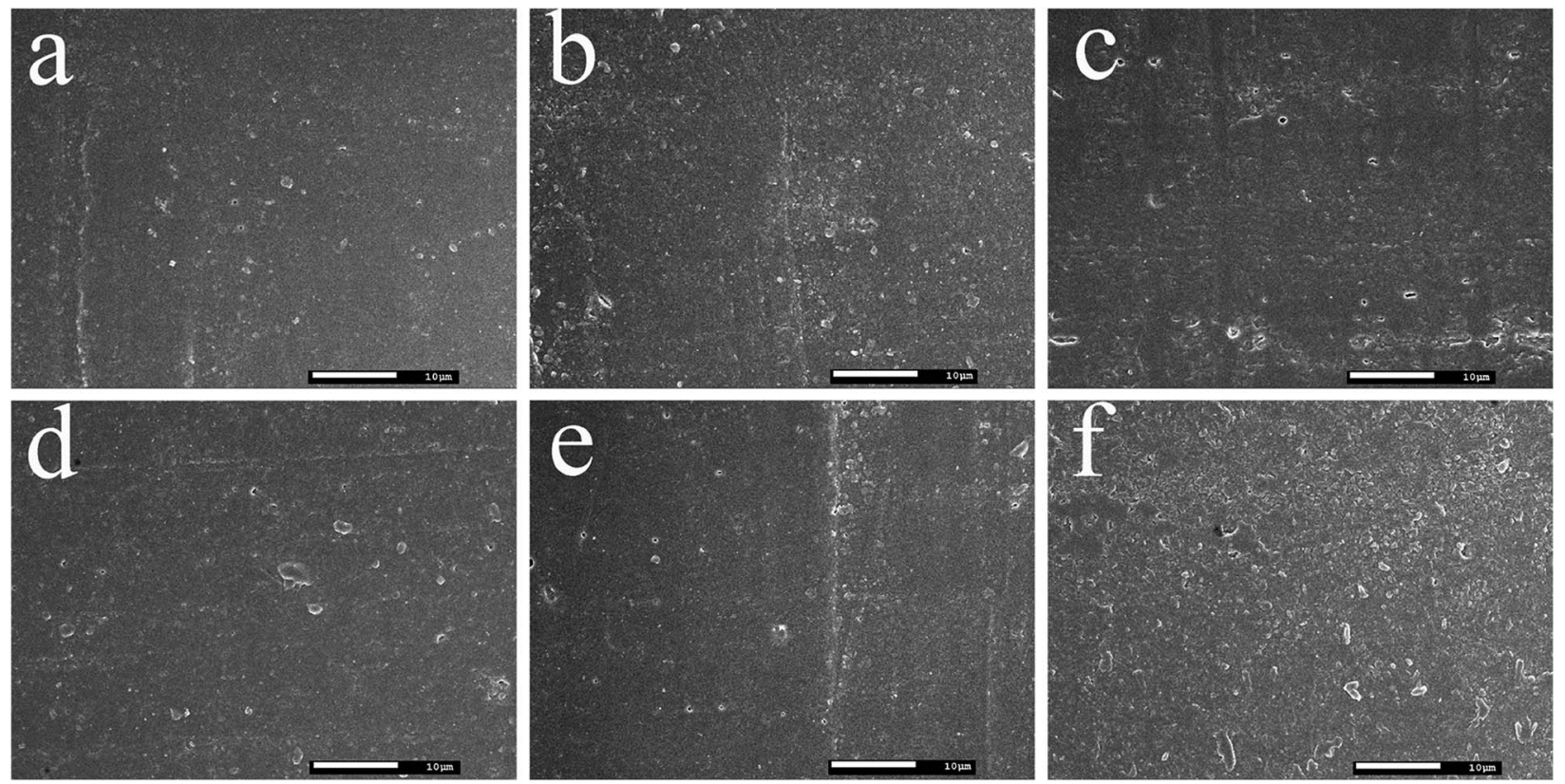

Fig. 12 SEM images of the surfaces of the BF/NBR blocks $(2000 \times)$ worn under water lubrication at $30{ }^{\circ} \mathrm{C}$ : (a) BF0-pa; (b) BF12-pa; (c) BF30-pa; (d) BF0-per; (e) BF12-per; (f) BF30-per.

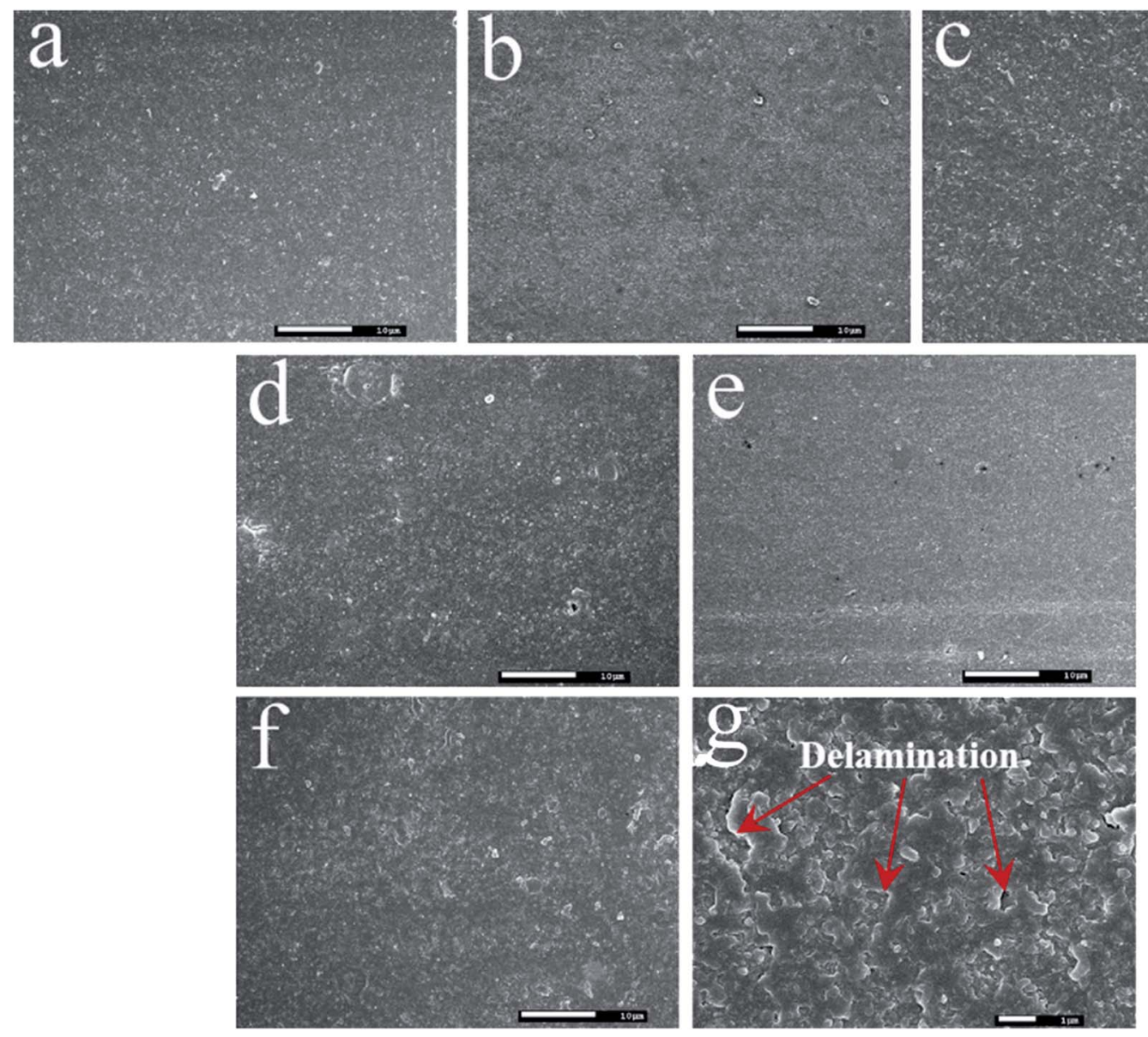

Fig. 13 SEM images of the surfaces of the BF/NBR blocks worn under water lubrication at $70{ }^{\circ} \mathrm{C}$ : (a) BF0-pa (2000 $)$ ); (b) BF12-pa (2000 $\times$ ); (c) BF30-pa (2000x); (d) BF0-per (2000x); (e) BF12-per (2000x); (f) BF30-per (2000×); and (g) BF30-per (10 000×). 


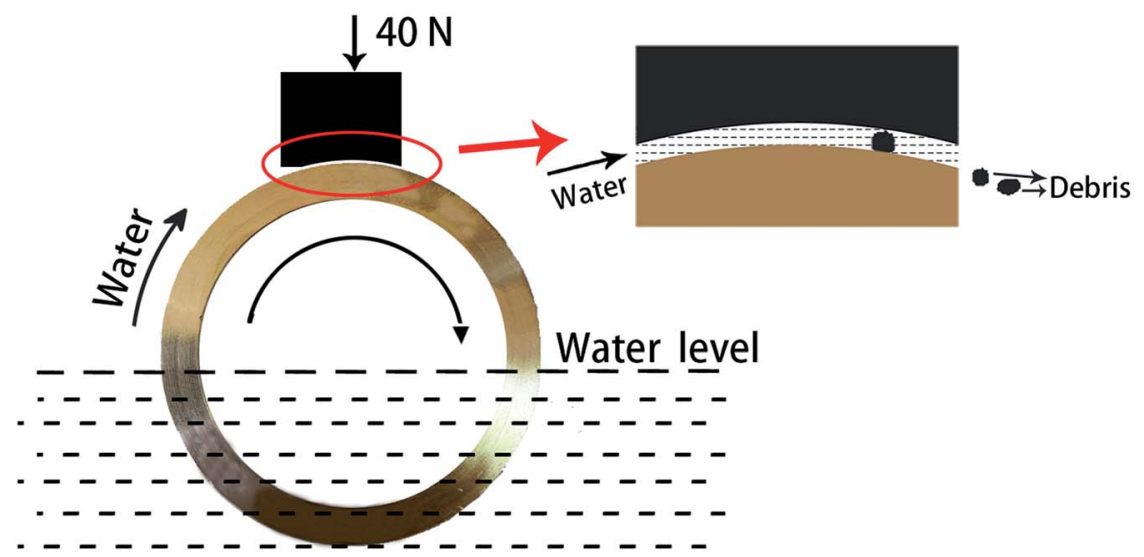

Fig. 14 Schematic of the rubbing between the BF/NBR block and the steel ring under the water-lubricated condition.

zooming in 10000 times (Fig. 13g). This aggravated wear of the composite block at high temperatures could be attributed to: (1) the insufficient lubrication of the water at $70{ }^{\circ} \mathrm{C}$ because of the viscosity decrease; (2) the loss of the effect of the water on reducing the heat that is produced by the rubbing process, which could lead to an increase in the adhesive wear; and (3) the decrease of the hardness and the tear strength of the BF/NBR surface after absorbing water at $70{ }^{\circ} \mathrm{C}$, which led to the increase of the contact area and aggravation of the surface fracture, respectively. These disadvantages led to an increase of the $W_{\mathrm{s}}$ of the composite block with temperature under the water lubrication condition, which is as shown in Fig. 10b.

\section{Conclusions}

To understand the water lubrication effect on the NBR-based composite at various temperatures and improve its wear resistance for the water-lubricated bearing application, this study investigated the tribological properties of the BF/NBR composites and 304\# stainless steel rubbing pairs under water lubrication at various temperatures. Based on our results, the conclusions are as follows:

(1) With the water temperature increase, the water absorption ratio and rebound resilience of the aged $\mathrm{BF} / \mathrm{NBR}$ composites significantly increased, whereas the hardness and tear strength decreased. For the composites with high BF content, the hardness and tear strength were more sensitive to the water temperature.

(2) Water provided excellent lubrication for the NBR-based composites at low temperature. With the increase of temperature from $30{ }^{\circ} \mathrm{C}$ to $70{ }^{\circ} \mathrm{C}$, the COFs for the $\mathrm{BF} / \mathrm{NBR}$ composites and the stainless steel rubbing pairs increased, whereas the content and the orientation of the BFs had less effect on the COF of the composites under water-lubricated conditions.

(3) With the temperature increase, the $W_{\mathrm{s}}$ of the $\mathrm{BF} / \mathrm{NBR}$ composites increased. The parallel-oriented BFs showed an obvious effect on the wear resistance improvement under waterlubricated conditions at both $30{ }^{\circ} \mathrm{C}$ and $70{ }^{\circ} \mathrm{C}$, whereas the addition of perpendicularly-aligned BFs showed a lower effect.
Generally speaking, NBR-based composites with parallelaligned BFs showed good wear resistance under water lubrication at a wide range of temperatures, and has potential to be applied in the water-lubricated bearing field.

\section{Conflicts of interest}

There are no conflicts to declare.

\section{Acknowledgements}

The authors acknowledge the financial support from the National Natural Science Foundation of China (grant number 51603110).

\section{References}

1 C. L. Dong, C. Q. Yuan, X. Q. Bai, Y. Yang and X. P. Yan, Study on wear behaviours for NBR/stainless steel under sand water-lubricated conditions, Wear, 2015, 332-333, 10121020.

2 H. L. Qin, X. C. Zhou, X. Z. Zhao, J. T. Xing and Z. M. Yan, A new rubber/UHMWPE alloy for water-lubricated stern bearings, Wear, 2015, 328-329, 257-261.

3 D. Hu, Z. W. Guo, X. Xie and C. Q. Yuan, Effect of sphericalconvex surface texture on tribological performance of waterlubricated bearing, Tribol. Int., 2019, 134, 341-351.

4 J. Z. Wang, B. B. Chen, N. Liu, G. F. Han and F. Y. Yan, Combined effects of fiber/matrix interface and water absorption on the tribological behaviors of waterlubricated polytetrafluoroethylene-based composites reinforced with carbon and basalt fibers, Composites, Part A, 2014, 59, 85-92.

5 C. L. Dong, C. Q. Yuan, L. Wang, W. Liu, X. Q. Bai and X. P. Yan, Tribological properties of water-lubricated rubber materials after modification by $\mathrm{MoS}_{2}$ nanoparticles, Sci. Rep., 2016, 6, 35023.

6 Z. L. Xie, N. Ta and Z. S. Rao, The lubrication performance of water lubricated bearing with consideration of wall slip and inertial force, J. Hydrodyn., 2017, 29, 52-60. 
7 S. B. Liu and B. G. Yang, Optimal placement of waterlubricated rubber bearings for vibration reduction of flexible multistage rotor systems, J. Sound Vib., 2017, 407, 332-349.

$8 \mathrm{~W}$. Litwin, Influence of local bush wear on water lubricated sliding bearing load carrying capacity, Tribol. Int., 2016, 103, 352-358.

9 X. Liang, Z. W. Guo, T. Jun and C. Q. Yuan, Effect of modified glass fiber on tribological performance of water-lubricated bearing, Polym. Test., DOI: 10.1016/ j.polymertesting.2019.106153.

10 H. H. Feng, S. Y. Jiang and A. M. Ji, Investigations of the static and dynamic characteristics of water-lubricated hydrodynamic journal bearing considering turbulent, thermohydrodynamic and misaligned effects, Tribol. Int., 2019, 130, 245-260.

11 H. J. Wang, Z. L. Liu, L. Zou and J. Yang, Influence of both friction and wear on the vibration of marine water lubricated rubber bearing, Wear, 2017, 376-377, 920-930.

12 W. Litwin and C. Dymarski, Experimental research on waterlubricated marine stern tube bearings in conditions of improper lubrication and cooling causing rapid bush wear, Tribol. Int., 2016, 95, 449-455.

13 J. Yang, Z. L. Liu, Q. C. Cheng, X. K. Liu and T. Y. Deng, The effect of wear on the frictional vibration suppression of water-lubricated rubber slat with/without surface texture, Wear, 2019, 426-427, 1304-1317.

$14 \mathrm{H}$. Hirani and M. Verma, Tribological study of elastomeric bearings for marine propeller shaft system, Tribol. Int., 2009, 42, 378-390.

15 S. W. Zhang, Green tribology: fundamentals and future development, Friction, 2013, 1, 186-194.

16 F. M. Kuang, X. C. Zhou, J. Huang, H. Wang and P. F. Zheng, Machine-vision-based assessment of frictional vibration in water-lubricated rubber stern bearings, Wear, 2019, 426427, 760-769.

17 Y. Q. Wang, X. J. Shi and L. J. Zhang, Experimental and numerical study on water-lubricated rubber bearings, Ind. Lubr. Tribol., 2014, 66, 282-288.

18 Z. M. Yan, X. C. Zhou, H. L. Qin, W. Y. Niu, H. Wang, K. Liu and Y. M. Tang, Study on tribological and vibration performance of a new UHMWPE/graphite/NBR water lubricated bearing material, Wear, 2015, 332-333, 872-878.

19 J. Huang, X. C. Zhou, J. Wang, X. W. Tang and F. M. Kuang, Influence of temperature on friction of polymeric materials in water, Wear, 2019, 426-427, 868-876.
20 S. Mahanta, S. Samanta and M. Chandrasekaran, Processing and investigation of tribological properties of basalt epoxy composites, Mater. Today: Proc., 2017, 4, 8185-8191.

21 A. A. J. Kumar and V. Srinivasan, Wear behavior of chitosanfilled polylactic acid/basalt fiber hybrid composites, Adv. Polym. Technol., 2018, 37, 898-905.

22 S. F. Zhou, J. J. Wang, S. Z. Wang, X. Z. Ma, J. Huang, G. Z. Zhao and Y. Q. Liu, Facile preparation of multiscale graphene-basalt fiber reinforcements and their enhanced mechanical and tribological properties for polyamide 6 composites, Mater. Chem. Phys., 2018, 217, 315-322.

23 T. Zhang, H. T. Liu, D. K. Zhang and K. Chen, Mechanical and wear properties of polyetheretherketone composites filled with basalt fibres, Sci. Eng. Compos. Mater., 2019, 26, 317-326.

24 S. F. Zhou, J. J. Gao, J. J. Wang, S. Z. Wang, J. F. Yue, C. S. Dong, J. Huang, G. Z. Zhao and Y. Q. Liu, Polydopamine-coupling of carbon nanotubes onto microscaled basalt fiber to enhancing mechanical, thermal and tribological properties of composite materials, Mater. Res. Express, 2019, 6, 0850g6.

25 Y. Z. Li, Z. Li, J. J. Wan, Z. Q. Yan, J. T. Sun and S. G. Zhao, Mechanical and tribological performance of chopped basalt fiber/acrylonitrile-butadiene rubber composites, Polym. Compos., 2019, 40, 630-637.

26 Z. Li, Y. Z. Li, J. M. Cheng, X. Y. Lu and Y. H. Yang, Effects of fibre content and orientation on the wear resistance of basalt fibre/acrylonitrile-butadiene rubber composites under various friction conditions, Iran. Polym. J., under review.

27 Y. Q. Li, Q. H. Wang, T. M. Wang and G. Q. Pan, Preparation and tribological properties of graphene oxide/nitrile rubber nanocomposites, J. Mater. Sci., 2012, 47, 730-738.

28 B. B. Chen, J. Yang, J. Z. Wang, N. Liu, H. P. Li and F. Y. Yan, Fiber hybrid polyimide-based composites reinforced with carbon fiber and poly- $p$-phenylene benzobisthiazole fiber: tribological behaviors under sea water lubrication, Polym. Compos., 2016, 37, 1650-1658.

29 N. Liu, J. Z. Wang, J. Yang, G. F. Han and F. Y. Yan, Enhancement on interlaminar shear strength and waterlubricated tribological performance of high-strength glass fabric/phenolic laminate by the incorporation of carbon nanotubes, Polym. Adv. Technol., 2014, 25, 1572-1579.

$30 \mathrm{~S}$. Meicke and R. Paasch, Seawater lubricated polymer journal bearings for use in wave energy converters, Renewable Energy, 2012, 39, 463-470.

31 J. A. Dean, Lange's handbook of chemistry, McGRAW-HILL INC., New York, 15th edn, 1999. 